\title{
Impact of Livelihood Diversification on Rural Household Food Security: Evidence from Goncha-Siso-Enesie Destrict of Amhara Regional State, Ethiopia
}

\author{
Esubalew Yenesew ${ }^{1,}$, Daniel Masresha ${ }^{2}$ \\ ${ }^{1}$ Department of Agricultural Economics, Raya University, Maichew, Ethiopia \\ ${ }^{2}$ Department of Agricultural Economics, Wollega University, Nekemte, Ethiopia
}

Email address:

esubalewemu@gmail.com (E. Yenesew)

*Corresponding author

To cite this article:

Esubalew Yenesew, Daniel Masresha. Impact of Livelihood Diversification on Rural Household Food Security: Evidence from Goncha-SisoEnesie Destrict of Amhara Regional State, Ethiopia. International Journal of Agricultural Economics. Vol. 4, No. 6, 2019 , pp. $288-297$. doi: 10.11648/j.ijae.20190406.16

Received: October 14, 2019; Accepted: December 2, 2019; Published: December 11, 2019

\begin{abstract}
Despite some improvements in recent years, widespread poverty and food insecurity remain the main challenges in Ethiopia. Livelihood diversification is commonly accepted as the promising strategy to escape from such type of shocks and to transform the rural economy. Ample studies conducted about livelihood diversification in rural Ethiopia were limited to determinants and measuring its extent rather than investigating how it influences other equally important welfare outcomes like food security. In light of these, this study attempted to analyse the impact of livelihood diversification on rural household food security in Goncha-Siso-Enesie district, Amhara Regional State of Ethiopia. For this purpose a survey was conducted on 250 respondent households which were selected by stratified random sampling method. Descriptive statistics were employed to analyse the data. To a large extent, impact of livelihood diversification on household's food security has been analyzed by using propensity score matching (PSM) econometric model. Descriptive statistics result pointed out that rural households combined non-farm and off-farm activities instead of relying on-farm only. Result from PSM also suggests that livelihood diversification brought a positive significant impact on household food security. Finally, policy implications were made according to the finding of the study.
\end{abstract}

Keywords: Livelihood Diversification, Food Security, Propensity Score Matching, Goncha-Siso-Enesie, Ethiopia

\section{Introduction}

Even if a number of development approaches employed such as the modernization theory, they failed to significantly eradicate poverty. Hence, in the early 1990s or so, the Sustainable Livelihood Approach (SLA) has inspired a new form of thinking, particularly regarding how development ought to be organized by drawing on advances in understanding of famine and food insecurity during the 1980 s $[14,19-11]$. It was found as key to poverty reduction and improvement of food security without much effect on the environment contrast to the previous developmental approach [7]. Following these considerations and experiences carried out in the previous decades, equity and sustainability have been added to economic growth as major measurements of policies and increasing attention has been paid to rural people's spontaneous adaptation to socioeconomic change [10-12].

According to the study by [12] which was carried out in seventeen countries from four developing regions (Asian, Latin America, Eastern Europe and Central Asia and SSAs) the income shares of on-farm is smaller in the four Asian countries, ranging from 26 percent to 48 percent, and smaller still in Latin American countries. In contrast, in SSAs more than half of total income came from on-farm activities (agriculture). The study also suggested that, relatively in this region lower share of income from non-agricultural wages were recorded, but the share from self-employment was lower significant. Therefore, the study shows that the SSAs are not entirely limited on agriculture only, but involved in 
some form of non-farm activity designed to diversify income sources [7].

However, the forms and levels of household's participation may differ from place to place [18]. Rural households in SSA diversify farm activities (by growing different crops and rearing different kinds of livestock), in off-farm activities (by working on other farms or engaging in natural resource related activities) and in non-farm activities (by engaging in wages labor, self-employment or labor migration). Some households may even straddle between three activities (farm, off-farm and nonfarm) over time depending on the opportunities and constraints they face [2].

Despite some improvements in recent years, poverty and food insecurity remains the main challenge due to climatic shocks (mainly as failure of rainfall and natural resource depletion) in Ethiopia. For instance, following the failure of rainfall during the 2015 agricultural seasons, estimates suggest that about 10.1 million people required emergency food assistance [12-20], 303,000 children requires treatment for severe acute malnutrition (SAM) in 2017 plus 2.7 million children and pregnant and lactating women in need of treatment for moderate acute [22]. Since Ethiopia is the only country where the rural households get an income of above 70 percent from on-farm activities relative to four sampled SSA countries [12], and this undiversified livelihoods aggravated the occurrence [9]. Similarly, Guncha-SisoEnesie district was identified as one of the food-insecure district from eleven districts in East Gojjam zone mainly attributed to climate shock, poor natural resource, soil infertility, mountainous and hilly topography, deforestation, and population pressure associated with small land size holding [1].

Having these problems, livelihood diversification has been identified as the most promising strategy in poverty reduction [10-2], in encouraging sustainable livelihoods [9], enabling of households to copy from shocks and stresses do not have long-lasting consequences on food security [4-7]. As a result, households in the study area were engaged in different livelihood activities like the sale of charcoal and firewood, fruits petty trade, labor exchange, migration, and etc to generate some income in addition to agriculture to fight mainly the food insecurity, but without detail awareness of its wider contribution in poverty reduction [1].

However, although it is apparent livelihood diversification influence household's livelihood, there is limited empirical evidence on how it influences other equally important welfare outcomes such as food consumption, education, health, and food security status of households [4]. Most studies were limited only to investigate the factors of household which impede to diversify, even if all agreed upon its absolute importance as a relevant to poverty reduction strategy. Further, the previous studies have also the following limitations. Firstly, studies like [9-26] were not employed the appropriate econometric model which minimizes the sample selection problem which is main task in impact evaluation. Secondly, some studies for instance [3, 4-9] tried to estimate its impact on general economic terms like poverty and welfare which are so difficult to proxy in single indicator. Thirdly, even if commercial forests (e.g. Eucalyptus) have high contribution for rural livelihood [8], but studies for example [4, 6-22] failed to estimate income from it or included as non-agricultural income by default and assets like communication and livestock have not been seen enough as determinants. Fourthly, studies for instance [4-7] were based on panel data which was not collected for such particular purpose and thereby different income generating activities were missed from the data.

In addition, by considering the non-homogeneity of characteristics of rural households in Ethiopia, analyzing its impact with locality specific is imperative. Therefore, in view of the aforesaid gaps and in order to formulate effective policies so as to improve the food security status of the households in the study area, it is significant to analyze the impact of livelihood diversification on food security status of rural households in Goncha-Siso-Enesie district. Hence; this article focused on estimating the impact of livelihood diversification on the food security status of rural households in Goncha-Siso-Enesie district.

The remaining part of the article is organized as follows. The second topic deals with a brief description of the research methodology, i.e. sample size and sampling techniques, data source, data collecting method, method of analysis, and econometric model specification. The result of the study is discussed in third topic. Finally, conclusion and policy recommendation of the study are presented in chapter four.

\section{Research Methodology}

\subsection{Description of the Study Area}

This study was carried out in rural district which is Goncha-Siso-Enesie. It is one of the eighteen districts of the east Gojjam zone. The district is about $335 \mathrm{~km}$ far from Addis Ababa which is the capital of Ethiopia. It is bordered in the south by Enarge-Enawuga district, in the north of South Gonder Zone, in the east by Enebsie-Sar-Mider district, and in the west by Hulet-Eju-Enesie district. At present, the district has 39 total Kebles, 2 urban and 37 rural Kebles and about $94.4 \%$ of the population resides in rural while the remaining $5.6 \%$ only are urban inhabitants. The dominant economic activity in the area is agriculture (mostly crop production and livestock husbandry as complementary). All crops, but especially commercial crops like wheat (macaroni, pasta, \& bread), teff, bean, lentil, maize, barley, sorghum, and others are cultivated in the area primarily depend on meher season.

\subsection{Sample Size and Sampling Techniques}

Small sample creates risk of drawing incorrect conclusions. So, three criteria's (parameters) are needed to be specified to determine the appropriate sample size. These are the level of precision $(\mathrm{e}=5 \%$ ), the level of confidence or risk $(\mathrm{t}=1.96)$, and the degree of variability in the attributes being 
measured (p) [20-15]. When $p$ is unknown, generally it is best to set it at 0.5 [15]. But, a proportion of $50 \%$ indicates a greater level of variability than either $80 \%$ or $20 \%$ [20-15] and a proportion of 0.5 indicates the maximum variability in a population, it is often used in determining a more conservative sample size, that is, the sample size may be larger than if the true variability of the population attributes were used [20]. Therefore, for this study the $p$ value was set as $80 \%$ \& $20 \%$. The Choucheran's formula specified as;

$$
n=\frac{t^{2} p(1-p)}{e^{2}}
$$

Therefore, $n=\frac{(1.96)^{2} * 0.8(1-0.8)}{0.005^{2}}=246$. But, to reduce sampling error $14(10 \%)$ more respondents were added and then 260 sample respondents was drawn.

After identifying the sample size the study used stratified random sampling technique. Studies conducted in rural household livelihood stratified their study area based on agro-ecology [22]. Similarly, in this study kebeles were stratified based on agrological zones since the district is classified into three on the basis of the altitude; high, mid, and low-altitude with the respective kebeles, 6, 21, and 10, respectively. Accordingly, four kebles were selected randomly from all agro-ecology zones, two kebeles from high and low land agro-ecological zones and the remaining two kebeles were selected from mid- altitude agro-ecological zones since it covers 21 kebeles. Finally, the calculated 260 sample respondents were selected from each four kebeles randomly and proportional to their population, out of which only 250 households gave required complete information. Hence, these 250 households constituted the sample size for the study.

\subsection{Data Type, Source and Collection Technique}

This study used both quantitative and qualitative data which were collected from both secondary and primary sources. Structured questionnaires, focus group discussions, and key informant interviews were employed as a tool to collect the necessary data. Focus group discussion and key informants were meant to gain additional qualitative information, while structured questionnaire was prepared and used in view of the main objective of the study.

\subsection{Methods of Data Analysis}

\subsubsection{Measuring Livelihood Diversification and Food Security}

As indicated by Blocka \& Webb (2001) and [22], non-farm and off-farm (non-basic activity) income share respective of households total income by using agriculture as the main income source can be used to classify the rural households as diversified or non-diversified. So, a household whose income from agriculture (basic source) greater than and equal to half $(50 \%)$ of his total income was considered as diversified, while a household whose income from agriculture (on-farm) was greater than this threshold $(50 \%)$ considered as nondiversified households.
Consumption (calorie intake) approach was employed to measure the food security status of the households [22]. It conducted based on the data obtained from households own food production, purchased and aided from others by asking the kind and amounts of food which they consumed (served) for limited periods in this case one week before interviewing date for the purpose of recall. In converting the physical food quantities consumed by a household into food calories adjusted for household age and sex composition we followed four steps. First, local measurement units were converted into a common unit of measurement for each food item consumed. Second, each of the food items consumed was converted into calories using the recommended conversion factor. Third, all food calories consumed were then added-up and converted into daily amounts. Finally, the aggregate food calories were adjusted in an adult equivalent unit per household.

\subsubsection{Econometrics Model (Propensity Score Matching)}

The foremost task of impact evaluation study is to overcome the self-selection problem [16]. To accomplish this, even though there are different types of impact assessment methods, propensity score matching method (PSM) was employed because of the following reasons. First, the PSM is the appropriate model when there is no panel dataset (in cross-sectional dataset) [24], second, the model simplify the self-selection problem by estimating the propensity score (probabilities of household to participate in livelihood diversification) and matching the propensity scores of two groups of household within common support region [4-25]. Thirdly, the model enables us to estimate the average impact (ATT \& ATU) of livelihood diversification on household's food security [16].

Applying Propensity score matching model (PSM): PSM consist propensity score (i.e. probability of participating in the treatment conditional on the characteristics $\mathrm{X}_{\mathrm{i}}$ ) and matching (i.e. find participants and non-participants with equal/similar propensity score). The consecutive steps in implementing PSM were estimation of the propensity scores, choosing matching algorithm, checking on common support condition and testing the matching quality.

Estimation of propensity score: It is the first step attempted to remove curse of dimensionality which was recommended by Rosenbaum and Rubin (1983) by matching on a single index (propensity score). Normally, logit or probit function is recommended for this purpose since treatment is typically dichotomous (i.e., $D=1$ for the treated (diversified) and $D=0$ for untreated (not diversified) units [15-25]. The logit assumes a logistic distribution of the error term and the probit assumes a normal distribution, but both logistic and normal distributions generally give similar results in practice. So, logit model was employed to estimate the propensity score in this study.

$$
\mathrm{P}(\mathrm{X})=\operatorname{pr}(\mathrm{D}=1 / \mathrm{X})
$$

Checking for assumptions: Before matching the estimated propensity score, the underlying assumptions were 
considered in order to check whether a matching method effectively reduce selection bias or not. The average effect of livelihood diversification (ATT) has to be estimate only over the common support (CS) region [24], which contains the minimum and maximum propensity scores of treatment and control group households, respectively. It ensures the existence of a non-diversified analogue for each diversified household and existence of a diversified household for each non-diversified household. It was checked by visual analysis of propensity score distribution.

The other assumption is Conditional Independence Approach (CIA) and it states that all the variables that affect simultaneously D (treatment, in this case diversification) and $\mathrm{Y}$ (outcome, in this case food security) were observed [25]. Since there is no ways to check this assumption, theories and previous works were used to include all the influential covariates.

Choose among alternative matching algorithm: There is no one recommended matching algorithm and there is trade-off between them. However, Nearest Neighbor matching (NNM), Caliper Matching (CM), and Kernel Matching (KM) are commonly used algorithms and accordingly those were employed with different band width. As suggested by [24] the final choice of a matching estimator was guided by different criteria such as equal mean test referred to as the balancing test, pseudo-R2 and matched sample size. Further, [16] suggested the low mean standardized bias and low LRchi2 value revealed as the best estimator. Therefore, a matching estimator having balanced (insignificant mean differences in all explanatory variables) mean, bearing a low pseudo R2, chi ${ }^{2}$ and mean standardized biased value and also the one that results in large matched sample size was preferred in this study.

Assessing the matching quality: Difference among covariates were expected before matching, but after matching the covariates should balance in both groups and hence significant differences will not expect. Standardized bias, ttest, joint significance and Pseudo- $R^{2}$ commonly used to check this [16] thereby those tests were employed in this study.

Calculation of treatment effect: To execute this, there are two parameters; ATE and ATT, but ATE does not reveal the true impact of diversification. It might not be of relevance to policy makers since it does not consider into account the common support assumption [5-25]. This implies households who were highly motivated and the households who had extremely low motivated to diversify his livelihood included in treatment effect (ATE). Therefore, the average treatment effect on the treated (ATT) was computed to evaluate explicitly the impact on those for whom at least the probability to diversify was approximated.

It is the average of the difference between the outcomes of participants and matched control individuals [24-25].

$$
\mathrm{ATT}=\mathrm{E}(\mathrm{Y} 1-\mathrm{Y} 0 \mid \mathrm{D}=1)
$$

where $\mathrm{D}=1$ refers to the treatment.

We can rewrite ATT as,

$$
\mathrm{ATT}=\mathrm{E}(\mathrm{Y} 1 \mid \mathrm{D}=1)-\mathrm{E}(\mathrm{Y} 0 \mid \mathrm{D}=1),
$$

Or;

$$
\begin{gathered}
E(Y 1 \mid D=1]-E(Y 0 \mid D=0]=A T T+E(Y 0 \mid D= \\
1)-E(Y 0 \mid D=0)
\end{gathered}
$$

The difference between the left hand side equation and $A T T$ is the so-called self-selection bias. The true parameter $A T T$ is only identified if:

$$
E(Y 0 \mid D=1)-E(Y 0 \mid D=0)=0
$$

Sensitivity analysis: The unconfoundedness assumption either conditional on covariates or score is strong and almost impossible to test statistically. It could be easily violated if there are unobservable household characteristics simultaneously influencing the participation decision in livelihood diversification. Therefore, it is crucial to perform sensitivity or a robustness check of the estimated result from hidden bias.

There are several ways to check robustness of the findings. One approach is using the different matching methods to check consistency of the results with different matching techniques [24]. The other method which used commonly is applying direct nearest-neighbor matching with "nnmatch" command in stata instead of estimating the propensity score equation first [5-18]. The other is the Rosenbaum bounding approach which suggested by Rosenbaum (2002). PSM assumes as all covariates that affect the treatment and the outcome variable controlled. Therefore, this sensitivity analysis method designed to check how the ATT result deviate if the unobserved covariates have been allowed to differ among diversified and undiversified households. So, those three methods were done in this study to check the robustness.

\subsubsection{Definitions, Measurements and Formulation of Hypothesis}

Table 1. Summary of variables used in econometric model.

\begin{tabular}{ll}
\hline Treatment variable & Characteristics (Measurement) \\
\hline Livelihood of diversification & Dummy (1=if difersified, 0=if undiversified) \\
Outcome variable & Characteristics (Measurement) \\
Food security & Continous (calorie intake) \\
Explanatory variables & Characteristics (Measurnment) \\
Age of household & Continuous (Number of years) \\
Sex of household & Dummy $(1=$ male, $0=$ female) \\
\hline
\end{tabular}




\begin{tabular}{ll}
\hline Treatment variable & Characteristics (Measurement) \\
\hline Educational level of household & Continuous (number of schooling years) \\
$\begin{array}{l}\text { Dependency ratio of household } \\
\text { Family size of hosehold }\end{array}$ & Continuous (dependant to labor force ratio \\
Farm size of household & Continuous (adult equivalent) + \\
Irrigation use & Continuous (number of timad) \\
Land fragmentation & Dummy $(1=$ if the HH use, $0=$ otherwise) \\
Livestock owning of household & Continuous (number of plots) \\
Cart ownership & Continuous (TLU) \\
Market distance & Dummy $(1=$ if owned, $0=$ otherwise) \\
Mobile phone & Continuous (household walking time) \\
Credit use & Dummy $1=$ if owned, $0=$ otherwise \\
Extension service & Dummy $(1=$ if the HH use, $0=$ otherwise) \\
Membership to cooperative & Continuous (number of contacts $)$ \\
Crop diversification & Dummy $(1=$ if a member, $0=$ otherwise $)$ \\
Agro-ecology & Continuous (ratios $)$ \\
\hline
\end{tabular}

\section{Results and Discussion}

\section{Introduction}

This section presents the socio-demographic characteristics, livelihood strategies of household's and the implementation of propensity score matching (PSM) to evaluate the impact of livelihood diversification on household food security. More precisely, it presents the estimation of the propensity score, common support region, matching algorithm and balancing test. At the end it provides the estimation of livelihood diversification impact among the diversified households.

\subsection{Socio-demographic Characteristics and Livelihood Strategies of Sampled Households}

From the total households under analysis about $81 \%$ of the households were male headed while, $19 \%$ of households were female headed. From these, 84, 6, 7, and $3 \%$ of households were married, widowed, divorced, and single, respectively. About $63 \%$ of the households reported as they used separated kitchen and corral for their livestock, while $37 \%$ of the respondent reported as they used the same house. In case of access to clean water, from 250 total households about $38 \%$ of the households accessed for clean water (rural clean water provided by the government and different organizations), while $62 \%$ of the households reported as they did not accessed for clean water instead they used the river, spring and pond water. In terms of educational level of the sampled population, about, 39, 32, 21, and 8 percent were found illiterate, informal (religious and adult educated), primary and secondary school finished. In communication asset about 42 percent of respondents reported as there is at least one mobile phone user in the household, while 68 percent of the households reported as they did not own.

Livelihood strategies were grouped based on clustering the sources of income that were identified in the study area. In the study area, smallholder farm households obtained their household income from three major categories of livelihood activities which include on-farm, non-farm, and off-farm activities.

Households participate in on-farm activities; crop production (like Teff, Maize, Wheat, Nut, Lentil, Bean, Vetch, Sorghum and Barely), animal husbandry (like cattle, sheep, goats, donkey, horse, mule and poultry), forestry and bee keeping activities. Based on the survey result, the majority $(97.5 \%)$ households were engaged in rearing at least one of the livestock types. Off-farm activities refer to agricultural activities which take place outside own farm [26]. Hence, local daily wage labor at village level, firewood and charcoal selling, renting of land and animals are the main source of off-farm income for households. From the total sampled households, only $22 \%$ of the respondents find to participate at least in one off-farm activity while $78 \%$ of the households did not participate in any off-farm activities. However, majority $(65.6 \%)$ of the households engaged in agricultural wage labor, $21.5 \%$ of the households participated in charcoal and firewood selling and about $13.9 \%$ of the households were participating in other off-farm activities (such as renting land and animals, share-cropping out etc.).

The major non-farm activities identified in the study area include handicraft activities (weaving, spinning, carpentry, house mudding etc.), petty trade (grain trade, fruits and vegetable trade), selling of local drinks, trading of small ruminants and cattle, and remittance transfers within and across nations. From these, $14 \%$ of the households are engaged in non-farm activities with on-farm activities, while $86 \%$ of the households were not engaged in any one of nonfarm activities.

\subsection{Impact Estimation of Livelihood Diversification on Food Security}

Estimation of propensity score: The first task was estimating propensity scores based on the logistic model. As shown from the table below from the logistic model result, the Chi-square value is 59 with $1 \%$ significance level and it suggests the model is well fitted. The pseudo-R2 value is 0.1751 which is fairly low and it indicates diversified households do not have much distinct in overall characteristics and hence the matching between diversified and not diversified households becomes easier [22].

Here, the overall intention was to balance the observed covariates by using propensity score which estimated from logit model and a detailed interpretation for determinants was 
not discussed. However to mention, from all included variables in to the model seven variables (farm size, adultequivalent, irrigation, crop diversification, cart ownership, credit use, and mobile phone) were found statistically significance. From those, farm size, adult-equivalent, irrigation, and crop diversification determined diversification of household's livelihood negatively at less than $10 \% \mathrm{p}$ value. On the other hand, cart ownership, mobile phone, and access to formal credit were statistically influence livelihood diversification positively.

Table 2. Estimation of Propensity Score: Dependent variable=Livelihood diversification (LD).

\begin{tabular}{|c|c|c|c|c|c|}
\hline LD & Coef. & Std. Err. & $\mathbf{Z}$ & $\mathbf{P}>\mathbf{Z}$ & Marg. effect (dy/dx) \\
\hline Agro-ecology & .2217 & .4086 & 0.54 & 0.587 & .0528 \\
\hline Sex of household head & .3084 & .3921 & 0.79 & 0.431 & .0705 \\
\hline Age of household head & -.0036 & .0145 & -0.25 & 0.801 & -.0009 \\
\hline Education level of $\mathrm{HHH}$ & .0034 & .0490 & 0.07 & 0.945 & .0008 \\
\hline Adult-equivalent & $-.2121 *$ & .1152 & -1.84 & 0.066 & -.0498 \\
\hline Dependency ratio & -.0857 & .1556 & -0.55 & 0.582 & -.0202 \\
\hline Farm size of household & $-.2171 * *$ & .0908 & -2.39 & 0.017 & -.0509 \\
\hline Land fragmentation & .1002 & .1312 & 0.76 & 0.445 & .0235 \\
\hline Livestock in TLU & .0301 & .0523 & 0.58 & 0.565 & .0071 \\
\hline Credit use & $.9191 * * *$ & .3256 & 2.82 & 0.005 & .2192 \\
\hline Extension contact & .0016 & .0572 & 0.03 & 0.976 & .0004 \\
\hline Market distance & -.0439 & .1421 & -0.31 & 0.757 & -.0104 \\
\hline Mobile phone & $.5518 *$ & .3118 & 1.77 & 0.077 & .1289 \\
\hline Membership to cooperative & .1423 & .3583 & 0.40 & 0.691 & .0331 \\
\hline Cart ownership & $.9388 * * *$ & .3378 & 2.78 & 0.005 & .2264 \\
\hline Constant & 1.4426 & 1.0959 & 1.32 & 0.188 & \\
\hline
\end{tabular}

Number of obs $=250$.

LR chi2 (17) $=59.07$.

Prob $>$ chi $2=0.0000$.

Log likelihood=-139.11653, Pseudo R2=0.1751.

Source: Own survey result, 2019. Note: ***,**, * stands for $1 \% 5 \%, 10 \%$ significance level respectively.

The common support condition: After estimation of propensity score checking the common support condition was the main task to processed the next step [24]. Therefore, here the predicted propensity score ranges from 0.0695931 to 0.9242723 with mean value of 0.5326902 for the diversified, while it ranges from 0.005991 to 0.8718667 with mean value of 0.3167767 for those undiversified households. So that, according to minima and maxima approaches [16] the common support region lies between 0.0695931 and 0.8718667 . Furthermore, the average propensity score among all sampled households was about 0.42 implying that the average probability to diversify livelihoods among sampled households was about 42 percent.

The figure below depicts the distribution of the propensity score among the group of households. As it shown, most of the diversified households were found in the right side but near to middle, while most of undiversified households were found in the left side of the distribution. Thus, it reveals that as there is enough overlap area in which the propensity score of both the diversified and the undiversified groups are similar. Therefore, the propensity score approached to zero (i.e. $<0.0695931)$ and the propensity score approached to one (i.e. $>0.8718667$ ) for non-diversified and diversified households, respectively failed to lie on the common support region. As suggested by [4], all observations whose propensity scores are smaller than the minimum and larger than the maximum should be deleted. Accordingly, only 16 of observations ignored from analysis (10 from nondiversified and 6 from diversified households).

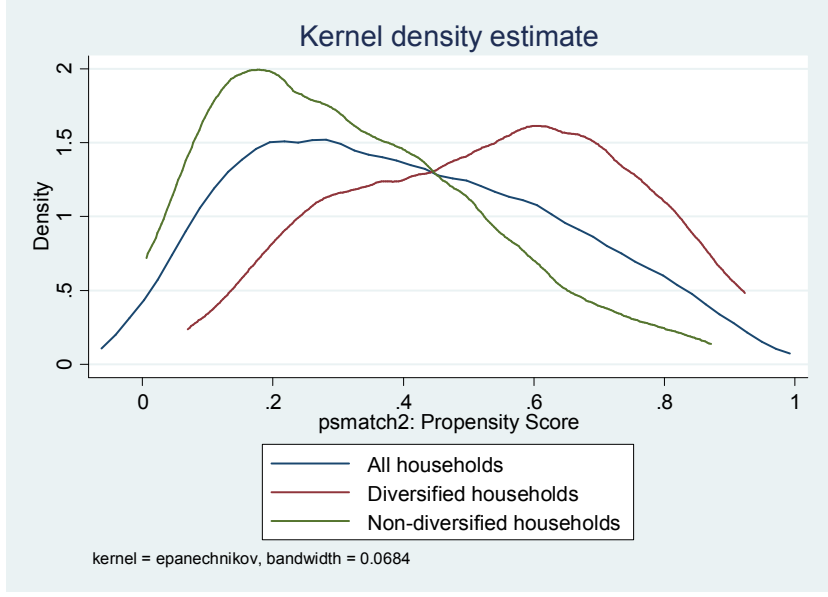

Figure 1. Kernel density of propensity score distribution.

Matching diversified and non-diversified households: As discussed in previously numerous criteria's were applied to select the best estimator. Hence, as shown in Table 3, nearest neighbor matching (NNM) estimator with neighbor 6 was selected. But, the estimation of ATT was not restricted in NNM 6 algorithm only. Further, radius matching (RM) estimator with bandwidth 0.05 and kernel matching (KM) 0.25 were employed as the next best alternative, to assess the consistence of the ATT in the same way as suggested by [26$18]$. 
Table 3. Performance of different matching estimators.

\begin{tabular}{|c|c|c|c|c|c|c|c|}
\hline \multirow{3}{*}{$\begin{array}{l}\text { Matching } \\
\text { algorithm }\end{array}$} & \multicolumn{7}{|c|}{ Performance criteria's } \\
\hline & \multirow[b]{2}{*}{ Pseudo R2 } & \multirow{2}{*}{ LR- chi2 (p>chi2) } & \multirow{2}{*}{ Mean std Bias } & \multirow{2}{*}{ Balancing test* } & \multicolumn{3}{|c|}{ Matched sample size } \\
\hline & & & & & Undiversified & Diversified & Total \\
\hline NNM1 & 0.083 & $22.11(0.227)$ & 10.2 & 14 & 140 & 96 & 236 \\
\hline 2 & 0.031 & $8.34(0.973)$ & 7.4 & 17 & 140 & 96 & 236 \\
\hline 3 & 0.026 & $6.91(0.991)$ & 7.0 & 17 & 140 & 96 & 236 \\
\hline 4 & 0.026 & $6.80(0.992)$ & 6.5 & 17 & 140 & 96 & 236 \\
\hline 5 & 0.022 & $5.81(0.997)$ & 5.8 & 17 & 140 & 96 & 236 \\
\hline 6 & 0.014 & $3.84(1.000)$ & 4.7 & 17 & 140 & 96 & 236 \\
\hline RM 0.1 & 0.029 & $5.83(0.997)$ & 4.3 & 17 & 68 & 83 & 151 \\
\hline 0.25 & 0.040 & $8.90(0.962)$ & 4.2 & 17 & 69 & 96 & 165 \\
\hline 0.5 & 0.074 & $18.63(0.415)$ & 8.0 & 16 & 88 & 96 & 184 \\
\hline 0.005 & 0.112 & $13.28(0.775)$ & 11.4 & 16 & 53 & 53 & 106 \\
\hline 0.05 & 0.068 & $12.23(0.835)$ & 8.8 & 16 & 68 & 76 & 144 \\
\hline KM 0.1 & 0.013 & $3.56(1.000)$ & 4.2 & 17 & 140 & 96 & 236 \\
\hline 0.25 & 0.015 & $3.87(1.000)$ & 6.2 & 17 & 140 & 96 & 236 \\
\hline 0.5 & 0.057 & $15.27(0.643)$ & 13.7 & 15 & 140 & 96 & 236 \\
\hline 0.05 & 0.017 & $4.60(0.999)$ & 4.5 & 17 & 140 & 96 & 236 \\
\hline
\end{tabular}

Source: Own survey result, 2019. Note: * is the number of explanatory variables with no statistically significant mean differences between the matched groups of diversified and non-diversified households. Values in parenthesis are standard deviation.

If there is significant difference in observed covariates among the groups after matching, the PSM model failed to solve the self-selection problem (World Bank, 2010). Therefore, the table posed below depicts the matching quality test of the selected estimator. It shows that, the balancing test of covariates before matching of diversified and notdiversified household heads were significantly different in many covariates. But, after matching no significant differences were observed between two groups in all covariates. The distribution of propensity scores before and after matching also indicates that estimating the p-score balances the diversified and not-diversified groups adequately. The fifth and sixth columns of the table shows, the standardized bias before and after matching and the total bias reduction obtained by the matching procedure, respectively. The standardized difference in covariates and propensity score before matching were in the range of $2.3 \%$ and $105 \%$, but it significantly reduced to the range of $0.2 \%$ and $13.1 \%$ after matching.

Table 4. Propensity score and covariate balance.

\begin{tabular}{|c|c|c|c|c|c|c|c|}
\hline \multirow{2}{*}{ Variable } & \multirow{2}{*}{ Sample } & \multicolumn{2}{|l|}{ Mean } & \multirow{2}{*}{ \%bias } & \multirow{2}{*}{$\begin{array}{l}\% \text { reduction } \\
\text { (bias) }\end{array}$} & \multicolumn{2}{|l|}{ T-test } \\
\hline & & Treated & Control & & & $\mathbf{T}$ & $p>t$ \\
\hline \multirow{2}{*}{ Propensity score } & Unmatched & 0.53269 & 0.31677 & 105.3 & & $8.23 * * *$ & 0 \\
\hline & Matched & 0.51356 & 0.5091 & 2.2 & 97.9 & 0.16 & 0.877 \\
\hline \multirow{2}{*}{ Agro-ecology } & Unmatched & 0.14851 & 0.18121 & -8.8 & & -0.68 & 0.499 \\
\hline & Matched & 0.15625 & 0.19444 & -10.3 & -16.8 & -0.69 & 0.489 \\
\hline \multirow{2}{*}{ Sex of HHH (1=Male) } & Unmatched & 0.82178 & 0.80537 & 4.2 & & 0.32 & 0.746 \\
\hline & Matched & 0.8125 & 0.83507 & -5.8 & -37.5 & 0.41 & 0.683 \\
\hline Age of household head & Matched & 47.406 & 47.382 & 0.2 & 94.1 & 0.02 & 0.988 \\
\hline \multirow{2}{*}{$\begin{array}{l}\text { Educational level of } \\
\text { household head }\end{array}$} & Unmatched & 2.802 & 2.8792 & -2.3 & & -0.18 & 0.858 \\
\hline & Matched & 2.7292 & 2.9427 & -6.4 & -176.6 & -0.44 & 0.661 \\
\hline \multirow{2}{*}{ Adult equivalent } & Unmatched & 4.5766 & 5.1689 & -40.7 & & $-3.16 * * *$ & 0.002 \\
\hline & Matched & 4.6749 & 4.7452 & -4.8 & 88.1 & -0.35 & 0.723 \\
\hline \multirow{2}{*}{ Dependency ratio } & Unmatched & 0.73384 & 1.1766 & -11.5 & & -0.82 & 0.412 \\
\hline & Matched & 0.75706 & 0.67572 & 2.1 & 81.6 & 0.92 & 0.359 \\
\hline \multirow{2}{*}{ Irrigation use (1=yes) } & Unmatched & 0.28713 & 0.48993 & -42.4 & & $-3.26 * * *$ & 0.001 \\
\hline & Matched & 0.29167 & 0.27604 & 3.3 & 92.3 & 0.24 & 0.811 \\
\hline \multirow{2}{*}{ Land fragmentation } & Unmatched & 2.7129 & 3.047 & -23.3 & & -1.82 & 0.07 \\
\hline & Matched & 2.7604 & 2.8351 & -5.2 & 77.7 & -0.36 & 0.717 \\
\hline \multirow{2}{*}{ Livestock in TLU } & Unmatched & 6.1532 & 7.0606 & -26.8 & & $-2.09 * *$ & 0.038 \\
\hline & Matched & 6.3357 & 6.2876 & 1.4 & 94.7 & 0.1 & 0.918 \\
\hline \multirow{2}{*}{ Credit contact (1=yes) } & Unmatched & 0.46535 & 0.24832 & 46.3 & & $3.64 * * *$ & 0 \\
\hline & Matched & 0.4375 & 0.42188 & 3.3 & 92.8 & 0.22 & 0.828 \\
\hline \multirow{2}{*}{ Extension contact } & Unmatched & 6.901 & 7.1275 & -8.3 & & -0.64 & 0.521 \\
\hline & Matched & 6.9896 & 7.1493 & -5.9 & 29.5 & -0.39 & 0.699 \\
\hline \multirow{2}{*}{ Market distance } & Unmatched & 1.557 & 1.7601 & -18.6 & & $-1.85 *$ & 0.094 \\
\hline & Matched & 1.5918 & 1.5553 & 3.3 & 82 & 0.24 & 0.813 \\
\hline
\end{tabular}




\begin{tabular}{|c|c|c|c|c|c|c|c|}
\hline \multirow{2}{*}{ Variable } & \multirow{2}{*}{ Sample } & \multicolumn{2}{|l|}{ Mean } & \multirow{2}{*}{ \%bias } & \multirow{2}{*}{$\begin{array}{l}\% \text { reduction } \\
\text { (bias) }\end{array}$} & \multicolumn{2}{|l|}{ T-test } \\
\hline & & Treated & Control & & & $\mathbf{T}$ & $p>t$ \\
\hline \multirow{2}{*}{ Mobile phone (1=yes) } & Unmatched & 0.60396 & 0.41611 & 38.1 & & $2.95 * * *$ & 0.003 \\
\hline & Matched & 0.58333 & 0.6059 & -4.6 & 88 & -0.32 & 0.752 \\
\hline \multirow{2}{*}{$\begin{array}{l}\text { Membership to cooperative } \\
(1=\text { yes })\end{array}$} & Unmatched & 0.72277 & 0.73826 & -3.5 & & -0.27 & 0.787 \\
\hline & Matched & 0.71875 & 0.71181 & 1.6 & 55.1 & 0.11 & 0.916 \\
\hline \multirow{2}{*}{ Crop diversification } & Unmatched & 0.38413 & 0.45001 & -34 & & $-2.63 * *$ & 0.009 \\
\hline & Matched & 0.39195 & 0.37829 & 7.1 & 79.3 & 0.48 & 0.632 \\
\hline Caret ownership (1=yes) & Matched & 0.33333 & 0.27604 & 13.1 & 66 & 0.86 & 0.391 \\
\hline
\end{tabular}

Source: Own survey result, 2019 . Note: $* * *, * *, *$ stands for $1 \% 5 \%, 10 \%$ significance level respectively.

Treatment effect on treated: The purpose of this all effort was to see whether the diversified households have significant difference in their food security status compared to non-diversified households or not. Therefore, the average treatment effect (ATT) result implied that, livelihood diversification brought statically significant positive impact on household's food security which was measured by calorie intake level or. It has been found that livelihood diversification increase household's calorie intake level in the range of 350.66 and $379.73 \mathrm{kcal}$ on average at less than $10 \%$ significant level for all estimators even though there is modest variation among algorithms. Thus, the result indicates that if the rural households diversify their livelihood, their food security status could be improved by 351 up to $380 \mathrm{kcal}$ on average. Similarly, according to the study by [22] which carried out in Oromia region, Ethiopia, diversification has been found that increase household's food consumption of diversified households by $587.19 \mathrm{kcal}$ on average. The study by [7] also finds that income diversification favours food accessibility, food availability, and food utilisation. Besides, the results also supported by the studies like [8-6], in which they conclude the positive effects of livelihood diversification on food security.

Table 5. Average treatment effects of livelihood diversification on treated by different estimator.

\begin{tabular}{lllllll}
\hline Algorithms & Outcome & Diversified & Non-diversified & ATT & SE & T-value \\
\hline NNM 6 & Calorie intake & 2951.85 & 2601.19 & 350.66 & 185.89 & $1.89^{*}$ \\
Kernel 0.05 & Calorie intake & 2951.85 & 2574.40 & 377.45 & 176.72 & $2.14^{* *}$ \\
Caliper 0.25 & Calorie intake & 2951.85 & 2572.13 & 379.73 & 165.08 & $2.30^{* *}$ \\
\hline
\end{tabular}

Source: Own survey result, 2019 . Note: ${ }^{* * *}, * * *$ stands for $1 \% 5 \%, 10 \%$ significance level respectively.

Checking the Robustness of ATT: To check whether the unobserved covariates determine the treatment and outcome variable simultaneously, different methods were undertaken. Even if there is variation in the size of ATT across estimators in the above, the impact is positive and significant for all at $\mathrm{p}<10 \%$ and confirms the consistency. The non-parametric (nnmatch) estimate also suggests diversified households have $509 \mathrm{kcal}$ more on average at $1 \%$ significance level (Table 6). Further, result from Rosenbaum bounding approach shows that, the impact is not changing though the diversified and non-diversified households have been allowed to differ in their odds of being diversified up to $100 \%$ (Gamma2) in terms of unobserved covariates (Table 7). This implies that the sensitivity of ATT is controlled up to doubled deviation in hidden covariates [5-18]. The significant $\gamma$ value further indicates that the study considered important covariates that affected both livelihood diversification and food security. Overall, it is possible to conclude that the impact estimates (ATT) is fairly insensitive to unobserved selection bias and is a pure effect of diversification on households' food security.

Table 6. Direct nearest neighbor matching result for checking robustness.

\begin{tabular}{lllllll}
\hline DNNM & Outcome & Coefficient & Std. Err. & $\mathbf{Z}$ & $\mathbf{P}>|\mathbf{z}|$ & [95\% Conf. Interval] \\
\hline DNNM1 & Calorie Intake & $509^{* * *}$ & 109.08 & 4.67 & 0.000 & 295.46723 .06 \\
\hline
\end{tabular}

Source: Own survey result, 2019. Note: ***, stands for $1 \%$ significance level.

Table 7. Rosenbaum bounding approach result for checking robustness.

\begin{tabular}{llllll}
\hline Outcome & Gamma1 & Gamma1.25 & Gamma1.5 & Gamma1.75 & Gamm2 \\
\hline Calorie Intake & $\mathrm{P}<0.00$ & $\mathrm{P}<0.00$ & $\mathrm{P}<2.0 \mathrm{e}^{-9}$ & $\mathrm{P}<.011254$ & $\mathrm{P}<1.3 \mathrm{e}^{-13}$ \\
\hline
\end{tabular}

Source: Own survey result, 2019.

But, the thing it needs caution is, PSM does not eliminate the bias resulting from confounding factor rather it reduces it, the sensitivity of ATT to hidden bias does not imply existence of unobservable only and these test statistics also does not imply the overall validity of CIA [18].

\section{Conclusion and Policy Implications}

\subsection{Conclusion}

The study was aimed to analyse the impact of livelihood 
diversification on household's food security stutus in Goncha-Siso-Enesie district. For this purpose, both the qualitative and quantitative data were employed which collected from both primary and secondary sources. Semistructured household survey questionnaire was prepared to collect the data from 250 selected sample respondents which used in view of the main objective of the study. Data analysis was made using descriptive statistics and propensity score matching model as econometric analysis mainly to circumvent self-selection problem.

From the descriptive statistics, more than half of the respondents were literate (both in informal and formal way) and about 39 percent of the household were illiterate. The respondents in the study area also finds as they engaged in off-farm (such as local daily wage labor, firewood and charcoal selling, renting of land and animals) and non-farm livelihood strategies (such as, handicraft activities, petty trade, selling of local drinks, and remittance transfers) in addition to their main livelihood strategies (agriculture).

Finally, this article sought to investigate the impact of livelihood diversification on household food security status (proxied by calorie intake) among rural households. The sophisticated econometric model propensity score matching was attempted for this purpose. And the result of the model shows that livelihood diversification brought a significant positive impact on rural household's food security status by showing a significant mean difference in caloric intake level between diversified and non-diversified households. To check the robustness of the estimation result (ATT), different sensitivity analyses were performed and the result confirmed its positive impact.

\subsection{Policy Implications}

Based on the finding of this study, policies improving the food security status of households in the study area should focus on:

Since, off-farm and non-farm activities have the potential to reduce some of the current pressure on rural households like small farm land size, land degradation and as a result food insecurity by providing alternative sources of income to rural households, policies which encouraged those activities should be expand.

Any policies targeted at promoting food security should go beyond just increase food production only; it needs to diversify rural household livelihood through the development of alternative livelihood opportunities to make it sustainable and self-resilience.

\section{References}

[1] Alemayehu, T. (2010, June 20). Nutrition Survey in Elleven Farmer Associations of Goncha Siso Enebse Woreda, East Gojjam Zone, Amhara Region.

[2] Alobo, H. S., \& Bignebat, C. (2017, June 1). Patterns and Determinants of Household Income Diversification in Rural Senegal and Kenya.
[3] Asfaw, S., Scognamillo, A., Di, G., Sitko, N., \& Ignaciuk, A. (2019). Heterogeneous impact of livelihood diversification on household welfare: Cross-country evidence from Sub-Saharan Africa. World Development.

[4] Bahadur, D., Abdul, K., \& Ali, A. (2017). Original Article Rural Livelihood Diversification Strategies and Household Welfare in Bhutan. The European Journal of Development Research.

[5] Carolyn. (2010). Applying, A Primer for Propensity-Score Matching. Office of Strategic Planning and Development Effectiveness, Inter-American Development Bank, USA.

[6] Chinedul et al. (2017). Effects of Livlihood Diversification on Food Security Status of Rural Farm Households in Abia State, Nigerea. Scientific Papers Series Management, Economic Engineering in Agriculture and Rural Development, 17 (1).

[7] Dedehouanou, S. F. A., \& Mcpeak, J. (2019). Diversify More or Less? Household Income Generation Strategies and Food Security in Rural Nigeria Diversify More or Less? Household Income Generation Strategies and Food Security in Rural.

[8] Dev et al. (2017). Analysis of the Impact of Income Diversification on Food Security Status of Rural Households in Bangladesh: A Case Study of Rajshahi District. American Journal of Theoretical and Applied Business.

[9] Ebenezer, M., \& Abbyssinia, M. (2018). Livelihood Diversification and Its Effect on Household Poverty in Eastern Cape Province, South Africa.

[10] Ellis. (2000). Rural Livelihood Diversity in Developing Countries. Oxford University Press, 3.

[11] FAO. (2009). Rural Livelihood Diversification and its Measurement Issues. Wye City on Statistics on Rural Developement and Agriculture Household Income. Rome, Italy.

[12] FAO. (2017). The State of Food and Agriculture. Leveraging Food System for Inclusive Rural Transformation.

[13] FAO. (2017, April). The State of Food Security and Nutrition in the World 2017. Building resilience for peace and food security.

[14] GLOPP. (2008). DFID's Sustainable Livelihoods Approach and its Framework. Department for International Developement.

[15] Greene, S. (2017, April 20). Methods for Determining Random Sample Size. UW-Stout Office of Planning, Assessment, Research and Quality.

[16] Marco, C., \& Sabine, K. (2005, May). Some Practical Guidance for the Implementation of Propensity Score Matching. Discussion Paper No. 1588.

[17] Osarfo, D. S.-A. (2016, May). The Impact of Nonfarm Activities on Rural Farm Household Income and Food Security in the Upper East and Upper West Regions of Ghana. Theoretical Economics.

[18] Roth et al. (2014). Estimation the Economic Effect of Remmittances on the Left-Behind in Cambodia. Partnership for Economic Policy, Cambodia.

[19] Serrat, O. (2008, November). The Sustainable Livelihoods Approach. Knowledge Solution. 
[20] Singh, A. S. (2014). Sampling Techniquee and Determination of Sample Size in Appplied Statistics Research: An Overview. International Journal of Economics, Commerce and Management.

[21] SOFI. (2017). The State of Food Security and Nutrition in the World. Annual.

[22] Titay, Z. (2013). Impact of Livelihood Diversification on Rural Households' Food Security in Fedis Weroda, Eastern Hararge Zone, Oromiya Regional State, Ethiopia. Journal of Poverty, Investment and Development: An International Peerreviewed Journal, 32.
[23] UNICEF. (2017). Ethiopia Humanitarian Situation Report. Ethiopia.

[24] World Bank. (2010). Handbook on Impact Evaluation; Quantitative Methods and Practices. Washington DC 20433.

[25] World Bank. (2016). Impact Evaluation in Practice (Second Edition ed.). Washington, D. C.

[26] Zerihun, B. (2016, June). Rural Non-Farm Diversification in Ethiopia: What Determines. The Centre for African and Oriental Studies. 